\title{
PERHITUNGAN KAPASITAS JALAN DAN TEBAL PERKERASAN JALAN PADA RUAS JALAN PROFESOR MOCH. YAMIN KABUPATEN CIANJUR
}

\author{
Yudi Sekaryadi \\ Dina Anjani \\ Program Studi Teknik Sipil \\ Fakultas Teknik Universitas Suryakancana
}

\begin{abstract}
ABSTRAK
Kapasitas adalah jumlah maksimum kendaraan atau orang yang dapat melintasi suatu titik pada lajur jalan pada periode waktu tertentu dalam kondisi jalan tertentu atau merupakan arus maksimum yang dapat dilewatkan pada suatu ruas jalan. Apabila diamati secara kasat mata jumlah kendaraan yang melintasi jalan Prof. Moch Yamin cukup tinggi, mengingat jumlah kendaraan LHR

Dari Perhitungan Kapasitas pada ruas jalan Prof. Moh Yamin didapat nilai Kapasitas Jalan Perkotaan $\mathrm{C}=2371$ dan Nilai Kapasitas Dasar $\mathrm{Co}=3100$, maka tidak diperlukan pelebaran jalan karena kapasitas masih memenuhi. Jalan tersebut dilakukan pelapisan tambahan dikarenakan jalan kurang baik, dari perhitungan pelapisan pada ruas jalan tersebut dilakukan dengan metode perkerasan lentur dengan Rencana Anggaran Biaya (RAB) sebesar Rp. 2.186.451.550
\end{abstract}

\section{Kata Kunci: Ruas Jalan, Kapasitas Jalan, Perkerasan Lentur}

\section{PENDAHULUAN}

Transportasi pada hakekatnya telah dikenal secara alamiah semenjak manusia ada di bumi, meskipun pergerakan/perpindahan manusia atau barang masih dilakukan secara sederhana. Perkembangan yang begitu cepat ini diakibatkan karena kebutuhan akan transportasi meningkat dengan tajam.

Jalan merupakan salah satu prasarana transportasi yang sering digunakan, jalan mempunyai peranan penting dalam kehidupan khususnya untuk kelancaran transportasi.

Tentunya diharapkan Jalan yang aman, nyaman dan lancar menjadi kebutuhan yang harus terpenuhi demi mencapai citi-cita bersama. Artinya lintasan yaitu sebagai tanah yang diperkeras atau jalan tanah tanpa perkerasan, sedangkan lalu lintas yaitu semua benda dan makhluk hidup yang melewati jalan tersebut baik itu manusia, hewan, kendaraan bermotor, maupun tidak bermotor.
Meningkatnya kemacetan pada jalan perkotaan maupun jalan luar kota yang diakibatkan bertambahnya kepemilikan kendaraan, terbatasnya sumber daya untuk membangun jalan raya, dan belum optimalnya pengoprasian fasilitas lalu lintas merupakan persoalan utama dibanyak negara.

Kemacetan selain menyebabkan menurunnya produktivitas karena terbuangnya waktu untuk melakukan perjalanan, disadari atau tidak menjadi penyumbang terbesar dalam penurunan kualitas udara. Polusi CO2 dari kendaraan bermotor telah membawa dampak negatif bagi kesehatan masyarakat. Selain berdampak secara fisik, dampak negatif kemacetan dalam jangka panjang akan berpengaruh terhadap kondisi mental masyarakat yaitu meningkatnya tingkat stress. Oleh sebab itulah, masalah kemacetan perlu diidentifikasi sejak awal, deteksi pemicu terjadinya kemacetan perlu diantisipasi sedini mungkin dan solusi serta 
kebijakan yang tepat perlu dilakukan. Perlu diketahui meningkatnya jumlah kendaraan bukanlah faktor utama penyebab terjadinya kemacetan, ada beberapa faktor lain yang selama ini tidak kita sadari.

Dengan permasalahan yang ada penulis menganggap pentingnya solusi kemacetan lalu lintas pada jalan Profesor Moh Yamin Kabupaten Cianjur oleh karena itu penulis memilih kemacetan lalu lintas sebagai studi kasus.

\section{METODOLOGI PENELITIAN}

Proses perencanaan dalam melakukan penelitian perlu dilakukan analisis yang teliti, pada pembahasan ini mengenai metode penyelesaian masalah pada ruas jalan Profesor Moh. Yamin KM BDG $63 \pm 94-64$ \pm 94. Analisis yang baik memerlukan pengumpulan data berupa data arus lalu lintas, Cbr, Pertumbuhan lalu lintas, koefisien lalu lintas, dan untuk perhitungan kapasitas, menggunakan MKJI.

\subsection{Pengumpulan Data}

\section{A. Data Primer}

Pada tahapan pengumpulan data primer ini, penulis melakukan survey langsung ke lapangan yang berlokasi di jalan Profesor Moch. Yamin, untuk mengetahui kondisi perkerasan dan geometrik jalan, dan untuk mengetahui jumlah kendaraan dan tipe kendaraan yang lewat pada masing-masing segmen jalan, maka digunakan metode survey manual (Perhitungan volume lalu lintas secara manual). Perhitungan volume lalu lintas dilakukan selama 24 jam pada hari Kerja, tepatnya pada hari Senin tanggal 13 Maret 2017. Survey yang dilakukan antara lain:

1. Pengamatan mengenai lintas harian kendaraan/jam pada 2 arah.

2. Metoda Pengamatan Bergerak (Moving Car Observer).

3. Pengamatan mengenai geometrik jalan.

4. Pengamatan kerusakan perkerasan jalan yang telah terjadi.

B. Data Sekunder

Data sekunder merupakan data yang diperoleh dalam bentuk dokumen yang dikumpulkan oleh pihak lain dalam bentuk publikasi. Data sekunder diperoleh dari Dinas PU Bina Marga Kabupaten Cianjur dan Dinas Perhubungan Komunikasi dan Informatika Kabupaten Cianjur, antara lain:
1. Data daya dukung tanah berupa data CBR (California Bearing Ratio) yang didapat dari perencanaan teknis Jalan Raya Prof. Moch Yamin KM BDG 63 $\pm 94-64 \pm 94$.

2. Curah Hujan curah Daerah Kabupaten Cianjur bekisar $1750 \mathrm{~mm} / \mathrm{thn}$.

3. Jumlah Penduduk 0,9 juta, Maka kelas ukuran kota termasuk kategori Sedang.

Setelah data-data di atas sudah dirasa cukup, maka akan dilakukan analisa data berdasarkan data tersebut berdasarkan standar yang ada, sehingga dapat dihasilkan hasil evaluasi mengenai perkerasan dan geometrik jalan yang diteliti dan menghasilkan desain perkerasan dan geometrik jalan yang baru dan diharapkan dapat melayani beban lalu lintas sesuai dengan umur rencana dan geometrik jalan yang lebih nyaman dan aman bagi pengguna jalan.

\section{PENGOLAHAN DATA DAN PERHITUNGAN}

\subsection{Perhitungan Kapasitas Jalan}

Perhitungan kapasitas yang akan ditunjukan untuk mengetahui serta membandingkan nilai perencanaan yang sudah dilaksanakan oleh Bina Marga dengan perhitungan hasil penilitian. Dalam perhitungan kapasitas jalan raya, kajian yang dianalisa antara lain:

1) Analisa Kecepatan Arus Bebas

Dalam perhitungan arus lalu lintas dengan menggunakan beberapa tabel dan angka yang diperlukan, didapat sebagaimana telah disajikan sebagai berikut:

- $F V_{0}$ : Kecepatan arus bebas kendaraan $65 \mathrm{~km} / \mathrm{jam}$ (Mengunakan Tabel 2.2 Kecepatan Arus Bebas Kendaraan Ringan).

- $F V_{W}$ : Dengan lebar jalan 7 meter/2 lajur sehingga didapat 3,5 meter perlajur dan kondisi jalan datar, maka faktor penyesuaian lebar lajur lintas efektif didapat $0 \quad \mathrm{~km} / \mathrm{jam}$ (Menggunakan Tabel 2.3 Faktor Penyesuaian Lebar Jalur Lalu Lintas Efektif).

- $\quad F F V_{S F}$ : Pada jalan ini kelas hambatan samping dengan kedua lebar bahu 0,50 meter maka faktor penyesuaian kondisi hambatan samping menggunakan 0,85 
(Menggunakan Tabel 2.4 Faktor Penyesuaian Kondisi Hambatan Samping).

- $\quad F F V_{R C}$ : Penyesuaian ukuran kota pada kecepatan arus bebas untuk jalan luar kota sehingga diperoleh 0,90 (Menggunakan Tabel 2.5 Faktor Penyesuaian Ukuran Kota).

Berdasarkan data-data tersebut maka dapat dihitung dengan menggunakan rumus:

$$
\begin{gathered}
F V=\left(F V_{0}+F V_{W}\right) \times F F V_{S F} \times F F V_{R C} \\
(\mathrm{~km} / \mathrm{jam}) \\
F V=(65+0) \times 0,85 \times 0,90 \\
F V=49,72 \mathrm{~km} / \mathrm{jam}
\end{gathered}
$$

\section{2) Analisa Kapasitas}

Dalam perhitungan Kapasitas Jalan dengan menggunakan beberapa tabel dan angka yang diperlukan, didapat sebagaimana telah disajikan sebagai berikut:

- $\quad C_{0}$ : Kapasitas dasar (smp/jam) dengan kondisi jalan 2/2 UD tanpa terbagi maka didapat nilai 3100 (Menggunakan Tabel 2.8 Analisa Kapasitas dasar Co jalan Perkotaan).

- $\quad F C_{S P}$ : Faktor penyesuain distribusi arah dengan jenis jalan 2/2 UD tidak ada median dan presentasi 55-41 didapat nilai 0,97 (Menggunakan Tabel 2.9 Faktor Penyesuaian Ditribusi Arah).

- $\quad F C_{w}$ : Faktor penyesuaian untuk lebar jalur lalu lintas pada kapasitas jalan Perkotaan dengan jenis lajur 2/2 UD tak terbagi dan lebar jalur 7 meter, didapat nilai 1,00 (Menggunakan Tabel 2.10 Lebar Jalur Efektif).

- $\quad F C_{S F}$ : Faktor penyesuaian hambatan samping untuk pengarus hambatan samping pada ruas jalan Prof Moch. Yamin dengan lebar bahu 0,50 meter dibilang tinggi karna banyak kendaraan keluar masuk Perkantoran, gang, sekolah, minimarket. Sehingga didapat nilai 0,90 (Menggunakan Tabel 2.5 Faktor Penyesuaian Ukuran Kota).

Berdasarkan data-data tersebut maka dapat dihitung dengan menggunakan rumus:

$C=C_{0} \times F C_{S P} \times F C_{W} \times F C_{S F}$

$C=3100 \times 0,90 \times 1,00 \times 0,85$

$C=2371,5$ smp/jam

Dari perhitungan kapasitas jalan Prof Moch. Yamin telah didapat nilai Kapasitas
Dasar $\mathrm{Co}=3100$ lebih besar dari nilai Kapasitas Jalan Perkotaan C $=2371$ maka dari itu tidak diperlukan pelebaran jalan karena kapasitas masih memenuhi.

3) Derajat Kejenuhan

$$
\begin{aligned}
-\quad \text { Qdh } & =\text { LHRT } \times \mathrm{k} \times \mathrm{SP} \\
& =20803 \times 0,11 \times 58 \% \\
& =1327,23 \\
\frac{Q}{C} & =\frac{1327}{2371}=0,5 \\
-\quad \text { Qdh } & =\text { LHRT } \times \mathrm{k} \times \mathrm{SP} \\
& =20803 \times 0,11 \times 42 \% \\
& =961,09 \\
\frac{Q}{C} & =\frac{961}{2371}=0,4
\end{aligned}
$$

Berdasarkan hasil perhitungan arus jam perencana untuk kedua arah menunjukan bahwa kondisi lalu lintas Prof. Moch Yamin tidak mengalami kondisi jenuh, Untuk arah Sukabumi-Cianjur 0,5 dan Cianjur Sukabumi 0,4 .

\subsection{Perhitungan Perkerasan Lentur}

Dari perkembangan lalu lintas berdasarkan hasil survey yang telah dilakukan, untuk LHR pada tahun 2017 (awal umur rencana), Maka dihitung untuk LHR rata-rata pada akhir tahun rencana sebagai berikut:

a. Data lalu lintas: 2026

b. Umur Rencana: 10 tahun

c. Fungsi Jalan: Kolektor

d. Pertumbuhan lalu lintas

- Kendaraan Ringan $15 \%$

- Kendaraan Berat 8\%

Di dapat dari hasil perhitungan LHR pada Tahun 2026: 60551

Setelah lintas harian rata-rata pada awal rencana didapat, selanjutnya dicari nilai angka ekivalen beban sumbu kendaraan. Dan dilanjutkan mencari angka ekivalen dengan mengitung lintas ekivalen pemula, lintas ekivalen akhir, lintas ekivalen tengah, dan yang terakhir lintas ekivalen rencana.

\begin{tabular}{|l|c|c|c|c|c||}
\hline \multirow{2}{*}{ Jenis Kendaraan } & Berat & \multicolumn{3}{|c|}{ Roda } & \multirow{2}{*}{ Nilai E } \\
\cline { 2 - 5 } & Maksimal & Depan & & belakang & \\
\hline Kend Ringan & 2,0 & 0,0002 & + & 0,0002 & 0,0004 \\
\hline Pick-Up & 2,0 & 0,0002 & + & 0,0002 & 0,0004 \\
\hline Truck 2 as (L) & 6,0 & 0,2923 & + & 0,0251 & 0,3174 \\
\hline Truck 2 as (H) & 13 & 6,4419 & + & 0,554 & 6,9959 \\
\hline Bus & 8,0 & 0,9238 & + & 0,0794 & 1,0032 \\
\hline
\end{tabular}




$$
\mathrm{DO}=\frac{3,48}{0,40}=8,7 \mathrm{~cm}
$$

Berdasakan hasil perhitungan untuk lapis tambahan didapat kebutuhan tebal perkerasan diambil menjadi $9 \mathrm{~cm}$.

Tabel 4.6 Hasil Perhitungan Lintas Ekivalen Akhir (LEA)

\begin{tabular}{|l|c|c|c|c|c|}
\hline Jenis Kendaraan & $\begin{array}{c}\text { Berat } \\
\text { maksimum } \\
\text { (ton) }\end{array}$ & Nilai C & LHR & E & LEA \\
\hline Kend Ringan & 2,0 & 0,50 & 55954 & 0,0004 & 11,1908 \\
\hline Pick-Up & 2,0 & 0,50 & 3297 & 0,0004 & 0,6594 \\
\hline Truck 2 as & 8.3 & 0,50 & 935 & 0,3174 & 148,385 \\
\hline Truck 3 as & 18.2 & 0,50 & 173 & 6,9959 & 605,145 \\
\hline Bus Besar & 13.2 & 0,50 & 194 & 1,0032 & 97,310 \\
\hline \multicolumn{7}{|c|}{ ELEA } \\
\hline
\end{tabular}

Tabel 4.7 Hasil Perhitungan Lintas Ekivalen Tengah (LET)

\begin{tabular}{|c|c|c|}
\hline LET & $=$ & $\frac{\text { LEP }+ \text { LEA }}{2}$ \\
\hline LET & $=$ & $\frac{397,1279+862,6905}{2}$ \\
\hline LET & $=$ & 629,9092 \\
\hline
\end{tabular}

Tabel 4.8 Hasil Perhitungan Lintas Ekivalen Rencana (LER)

\begin{tabular}{|c|c|c|}
\hline LER & $=$ & LET $\times$ UR/10 \\
\hline LER & $=$ & $629,9092 \times 10 / 10$ \\
\hline LER & $=$ & 629,9092 \\
\hline
\end{tabular}

Berdasarkan grafik diatas didapat nilai CBR yang mewakili sebesar 5,5\% Maka daya dukung tanahnya di tentukan dengan rumus:

$$
\begin{aligned}
& D D T=4,3 \log (C B R)+1,7 \\
& D D T=4,3 \log (5,5)+1,7=4,8
\end{aligned}
$$

Sehingga didapat nilai DDT 4,8

Tabel 4.11 Kekuatan Relative

\begin{tabular}{|l|c|}
\hline \multicolumn{1}{|c|}{ Jenis Lapisan } & Koefisien Kekuatan Relative \\
\hline Laston $80 \%$ & 0,40 \\
\hline Batu pecah (LPA) & 0,13 \\
\hline Sirtu (LPB) & 0,12 \\
\hline
\end{tabular}

rencana 9,5 .

Berdasarkan data kekuatan jalan lama, maka sudah dapat menentukan tebal lapis tambahan dengan umur rencana 10 tahun, dengan perhitungan sebagai berikut:

LASTON: $80 \% \times 0,40 \times 7,75=2,48$

BATU PECAH: $90 \% \times 0,13 \times 20=2,34$

SIRTU: $100 \% \times 0,12 \times 10=1,2$

$$
\text { TTP yang ada } 6,02
$$

Jadi untuk lapis tambahan (overlay)

$$
\begin{aligned}
& \text { ITP }=\text { ITP } 10-\text { IT Pada } \\
& \text { ITP }=9,5-6,02=3,48 \\
& \text { ITP }=\text { a0 D0 } \\
& \quad 2,48=0,40 \text { D0 }
\end{aligned}
$$

Untuk penyesuaian perhitungan lapis tambahan, mengacu kepada spesipikasi Binamarga (2010), Dengan menggunakan Tabel 2.20 Nominal rancangan Campuran Aspal dan Toleransi, disajikan pada gambar

\begin{tabular}{|c|c|c|}
\hline \multicolumn{2}{|l|}{ Jenis Kendaraan } & $\begin{array}{c}\text { Jumlah } \\
\text { Kendar } \\
\text { aan }\end{array}$ \\
\hline \multicolumn{2}{|l|}{ Kendaraan Ringan } & 13831 \\
\hline \multicolumn{2}{|l|}{ Pick-up } & 815 \\
\hline \multicolumn{2}{|l|}{ Truck 2 as (L) } & 433 \\
\hline \multicolumn{2}{|l|}{ Truck 2 as $(\mathrm{H})$} & 80 \\
\hline \multicolumn{2}{|l|}{ Bus Besar } & 90 \\
\hline Laston ACWC 80\% & 7,75 & $\mathrm{~m}^{15250}$ \\
\hline Batu pecah $90 \%$ & $20 \mathrm{C}$ & $\mathrm{m}$ \\
\hline LPB sirtu $100 \%$ & $10 \mathrm{C}$ & $\mathrm{m}$ \\
\hline Total & & \\
\hline
\end{tabular}
sebagai berikut:

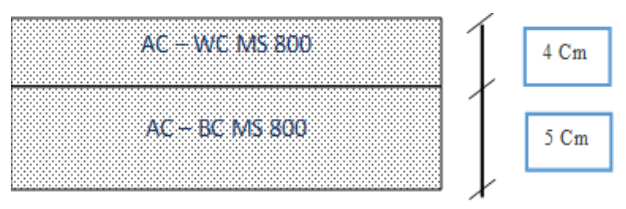

\subsection{Perhitungan Biaya Lapisan Tambahan}

Tabel 4.12 Rekapitulasi RAB

\section{Penutup}

\subsection{Kesimpulan}

jalan didapat Nilai Kapasitas Jalan Perkotaan (C) sebesar 2371 smp/jam, lebih besar dari nilai Kapasitas Dasar (Co) 3100, maka dari itu pada ruas jalan Prof. Moch. Yamin KM BDG $63 \pm 94-64 \pm 94$ tidak diperlukan pelebaran jalan, dikarenakan kapasitas masih memenuhui. 
- Derajat kejenuhan dihitung dengan menggunakan arus dan kapasitas dinyatakan dalam smp/jam. Besarnya derajat kejenuhan secara teoritis tidak bisa lebih nilai satu, maka rasio lalulintas pada ruas jalan Prof. Moch. Yamin KM BDG $63 \pm$

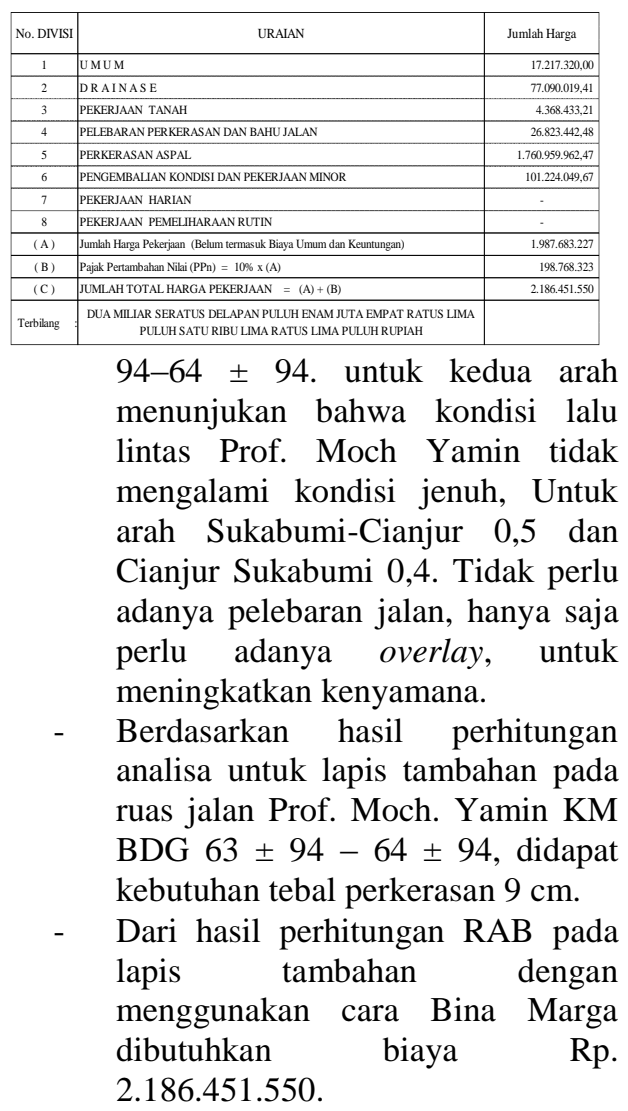

\subsection{Saran}

- Diperlukannya manajemem lalu lintas baik untuk mengurangi tundaan, antrian bahkan kemacetan yang terjadi. Agar perkerasan alan dapat terhindar dari kerusakan struktur, dan sesuai pada umur rencana.

- Perlu adanya rambu-rambu diarea ruas jalan Prof. Moch Yamin dan perlu adanya penerangan, Untuk mengurangi kejenuhan.

- Pada ruas jalan Prof Moch Yamin, diharuskan ada tempat parker sehingga tidak ada kendaraan yang parkir di ruas jalan, atau ada ketegasan dari pihak kepolisian dalam hal parker sembarangan.

- Diperlukannya kesadaran semua pihak khususnya pengguna jalan untuk menaati peraturan-peraturan lalu lintas yang berlaku di jalan tersebut.

\section{DAFTAR PUSTAKA}

Dewan Standardisasi Nasional, Tata Cara Perencanaan Tebal Perkerasan Lentur Jalan Raya dengan Metode Analisa Komponen, SNI 1732-1989-F, 1987

Dewan Standardisasi Nasiaonal Perencanaan Kota MKJI 1997

Dewan Standardisasi Nasional, Tata Cara Perencanaan Tebal Perkerasan Lentur Jalan Raya dengan Metode Analisa Komponen, SNI 1732-1989-F, 1987

Edward K. Morlok dan Johan K. Hainim, Pengantar Teknik \& Perencanaan

Ilham, Diktat Kuliah Perencangan Perkerasan Jalan.

Ilham, Diktat Kuliah Rekayasa Transportasi. Silvia Sukirman, Perkerasan Lentur Jalan Raya, Penerbit Nova, Bandung, tanpa tahun 
